Complutense Journal of English Studies

ISSN: 2386-3935

http://dx.doi.org/10.5209/CJES.56940

\title{
English Language Development in Nigerian Society: A Derivative of Advertising Communications
}

\author{
Taofeek Olaiwola Dalamu ${ }^{1}$
}

\begin{abstract}
Language, a central device in social domains, began from somewhere; and it has witnessed unstoppable development. The growing behaviour influenced this study with a goal to appraise the contributions of advertising in Nigeria to the development of English. Thus, thirtytwo creative-cum-new lexicons of $M T N^{\mathbb{B}}$ and Etisalat ${ }^{\mathbb{B}}$ served as analytical data. Morphological tools of derivation, compounding and blending assisted in processing the formation of novel words. The study revealed that the competitive market had informed copywriters to chart a new credible course. That spirit has motivated advertising experts to create exciting lexicons, which are convenient to sensitise readers. Given that factor, word formation processes become arbitrary where phonemic units $[k],[z],[j]$ and $[a]$ were employed to realise morphemic elements of Kulturefest, callertunez and Nigeria. Some formations follow compounding procedures (F@ stLink, biztime; 9javaganza and easyflex) as well as deviations (Thank Yous, hynet; wwwhenever and freeeee) to achieve persuasion. The construction of lexicons is fundamental, where MTN adopts Y'ello and Etisalat associates with $0809 \mathrm{ja}$ as business identities. As these constructs are fascinating and functional in the social system, the study suggested that lexicographers might take advantage of the development to integrate new lexemes in dictionaries, as observed from the Nigerian perspectives.
\end{abstract}

Keywords: Advertising Communication; Language, Language Development; Morphemes; Word Formation Processes.

\section{[es] El desarrollo de la lengua inglesa en la sociedad nigeriana: derivados de la comunicación publicitaria}

Resumen. El lenguaje, un dispositivo central en los dominios sociales, tuvo su origen en algún lugar y ha sido testigo de un desarrollo imparable. Este creciente desarrollo ha influido en este estudio con el objetivo de evaluar las contribuciones de la publicidad en Nigeria al desarrollo del inglés. Así, se han usado como datos analíticos treinta y dos léxicos creativos y nuevos de MTN $^{\circledR}$ y Etisalat ${ }^{\circledR}$. Las herramientas morfológicas de derivación, composición y mezcla ayudaron a procesar la formación de nuevas palabras. El estudio revela que el mercado competitivo ha arrojado información a los creadores para que estos tracen un nuevo rumbo que resulte creíble. Ese espíritu ha motivado a los expertos en publicidad a crear lexicones estimulantes que resulten adecuados para sensibilizar a los lectores. Teniendo en cuenta este factor, los procesos de formación de palabras se vuelven arbitrarios cuando las unidades fonémicas $[k],[z],[j]$ y $[a]$ son empleadas para crear elementos morfémicos de 'Kulturefest', 'callertunez' y 'Nigeria'. Algunas formaciones siguen los procedimientos de composición ( F @ stLink, biztime; 9javaganza y easyflex), así como desviaciones (Thank Yous, hynet; wwwhever y freeeee), para resultar persuasivas. La construcción de léxicos es fundamental, y se aprecia cómo MTN adopta a Y'ello y Etisalat se asocia con $0809 \mathrm{ja}$ como identidades comerciales. Dado que estos constructos son muy interesantes y funcionales en el sistema social, este estudio invita a los lexicógrafos a aprovechar

1 Department of English, University of Lagos, Akoka, Yaba (Lagos, Nigeria)

E-mail: lifegaters@yahoo.com. 
el desarrollo para que integren nuevos lexemas en los diccionarios, tal y como se observa desde esta perspectiva nigeriana.

Palabras clave: Comunicación publicitaria; Lenguaje, desarrollo del lenguaje; Morfemas; Procesos de formación de palabras.

Contents. 1. Introduction. 1.1. Morpheme, Word and Word Formation Processes. 1.2. Hierarchical Morphological Status. 2. Methodology. 2.1. Data Presentation. 3. Results. 4. Discussion. 4.1 MTN communications. 4.2 Etisalat communications. 5. Conclusion.

How to cite this article: Olaiwola Dalamu, T. (2018) English Language Development in Nigerian Society: A Derivative of Advertising Communications, in Complutense Journal of English Studies 26, 263-286.

\section{Introduction}

The development of language from a general perspective can come to the limelight in any form. A specific language (English or Yoruba) also enjoys the same benefit. This is because resources of different peculiarities contribute to what human beings label as language and the development that language undergoes. As a result of that remark, one could assert that language is never a static phenomenon. It is rather dynamic (Okoro 2006). The observable 'kinesis' positioning language as a living organism, the researcher could say, taps its currency from the growth and development that human beings and society experience. As human beings go about meeting their social needs, it is in the same manner that language grows with strengths to assist and satisfy human communication requisites. By implication, that dual developmental relationships are indicators of the centrality of language in the socio-cultural spheres (De Beaugrande 1991).

Although social performances of people add to the growth that language experiences; the contributions of academic disciplines is vast. The collective impacts of engineering, social sciences and the humanities are vital factors. In the academic domains, there are word creations with the affixation of -lity, -ism, etc. The manufacturing industry also contributes ideally to the language growth and development in society. Formations such as SCUBA (self-contained underwater breathing apparatus), Escalade, Microsoft, etc. are manifestations from the industrial environment. Among others, one could also reference CNN (Cable Network News), BBC (British Broadcasting Corporation), VOA (Voice of America), VON (Voice of Nigeria), NTA (Nigerian Television Authority), Aljazeera, The Punch, The Guardian, etc. as sophisticated facilities that creep into language use through the media. However, as these novel linguistic structures find their ways into human communication activities, no one can resist their permanence in the multifaceted society of ours. There is, perhaps, no alternative to their acceptance. In that regard, one might classify the advertising industry as a meetinghouse of text creators.

Nevertheless, Ubahakwe (1979) recognises the development to have discussed the varieties and deployments of English in the Nigerian domains. In a similar perspective Ricks and Marsh (1969) expound patterns and compositions of English, Pride (1982) articulates his thoughts on new Englishes, and Bauer 
and Renouf's (2001) study reflects on a corpus-based approach to compounding structures in English. Okoro (2006) analyses category shift and (2008) codifies the phases of development in Nigerian English. This investigation, as a contribution to earlier efforts on the growth and development of English in Nigeria, focuses on the formation of lexemes in advertising communications of $M T N^{\circledR}$ and Etisalat $^{\mathbb{B}}$. The idea is to exemplify how creativity in advertising has supported language growth and development. In other words, the study has analysed new lexicons, observed in advertising and how advertising professional's intention to persuade readers has turned out to add to the development of English in Nigerian society.

\subsection{Morpheme, Word and Word Formation Processes}

The study conceptualises three morphological terminologies as the domain of theoretical appreciations. These are morpheme, word and word formation processes. Generally, every structure of a language, as Zapata (2000) argues, operates within the ramifications of morphemes and words. However, the conduct of morphemic combinations to produce a word, for example in English, might be quite different from that of Yoruba. It is also in that vein that the process of their word formation might be different one from the other. Besides, a single word (lexeme) of a language might be a phrase or clause in another (e.g. Oluwatosin [Yoruba] - God is worthy to be praised [English]; Oluwatobi [Yoruba] - God is great [English]; Oluwatoyin [Yoruba] - God is worthy to be worshipped [English]). The inherent formative capacities of those words are different, but the meaning productions are similar. Though there are words that do not have corresponding (one-on-one) meanings in two different languages, sentential constructions could still vie adequate meaning potential.

Every word in a language has at least a morpheme, as earlier stated. This is owing to the proof that a morpheme is the smallest linguistic unit of a word (Booij 2007; Lieber 2010; Denham and Lobeck 2013). Consequently, without a morpheme, word formations and existence appear impossible. That is why Plag (2003) claims that a morpheme and perhaps its combination produce a word either as orthographic or as containing syllabic elements. Plag further sensitises readers that a word is a syllabic action and an entity possessing part of speech's specification. A word has a stress with an indivisible unit(s) of morphemes. In a similar point of view, Yule (1985: 60) describes a morpheme as 'a minimal unit of meaning or grammatical function.' This refers that a morpheme cannot undergo any other process of breaking the element down to another 'smallest particle.' A morpheme, as Yule submits, is grammatical. Both morphologists and language users combine morphemes that can produce relative meanings. As a result of Yule's (1985) thought, morphemic combinations must be grammatically organized for a purpose of meaningful linguistic derivatives.

As there are different appearances of words in a language, it is unarguable that their words formation processes concerning morphemic reactions will not be the same. Zapata (2007) throws some light to that, accentuating morphemes in their free and bound operations. Figure 1 below illustrates the morphological descriptions of morphemes. 


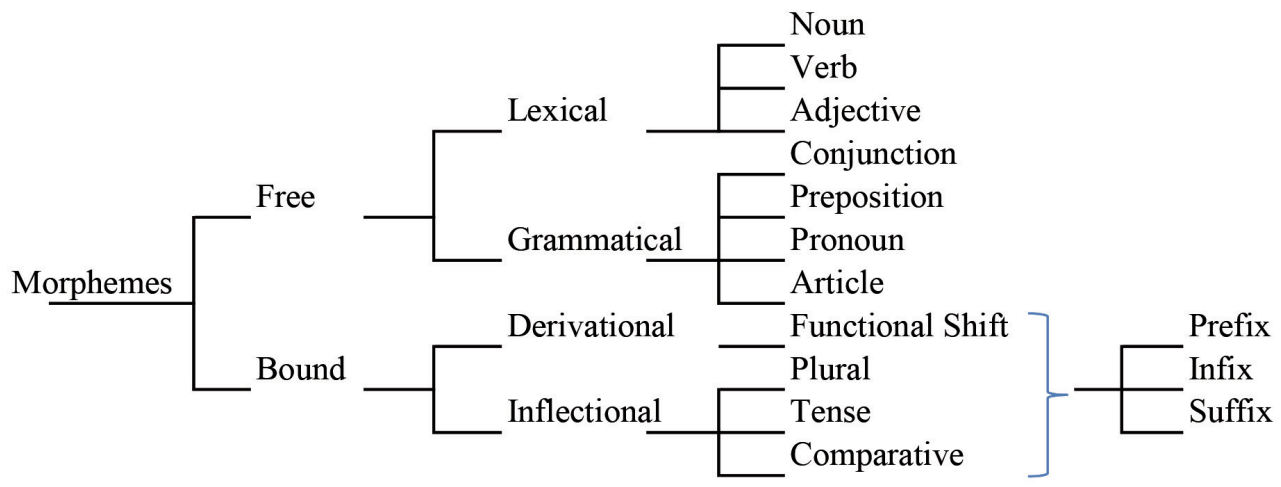

Figure 1. System of morphemes.

Lexical morphemes, as demonstrated in Figure 1, convey content messages regarding nouns (joy, reading), adjectives (specific, different) and verbs (sing, write). Grammatical morphemes facilitate functional words of conjunctions (and, but), prepositions (about, across), pronouns (he, she) and articles (the, a, an). Details are in (Aronoff 1976; Bauer 1983; O’Grady, Archibald, Aronoff and Rees-Miller 2005). Derivational morphemes influence the changes observed in word classes through the devices of -an, -ish, -il and pre-, etc. The domineering roles that inflectional morphemes play on lexemes are signals to plurality, comparability and tense structural associations of words (e.g. teacher - teachers; bright - brighter - brightest; come comes - coming - came). Nonetheless, both derivational and inflectional forms, Brown and Miller (1980); Akmanjian, Demers and Harnish (1984) explain, are products of affixation in the harmony of prefix, infix and suffix (also in Anderson 1992; Spencer 1992).

Apart from the derivational processes, blending, borrowing, coinage and compounding are contributors to word formation procedures. Other combinatory facilities are acronym, conversion, calques, clipping and back-formation (Hinnebusch 1979; Robins 1989; Jackson and Ze Amvela 2005). Blending is the joining of the beginning of a word to the end of the other, whereas borrowing points to loan-word from another language. Coinage and neologism come alive through the textual manipulation exercises. Compounding and acronym refer to the joining of two separate lexicons and the using of the initial letters of words to produce a word. On the contrary, clipping and backformation are the reduction of the syllables of a word in order to produce another one (Napoli 1996). Conversion implies a category change as well as a functional shift that assist in influencing the function of a word. Meaningful resources are in (Bauer 2006; Nolda 2014).

\subsection{Hierarchical Morphological Status}

Morphemes occupy the critical analytical centre-point of morphological appreciations. To this end, it is worth stressing that morphemes within words are organised in systematic linear patterns along with layered structures. Such arguments are not without constraints (Lieber 2005; Yule 2016). The strict formation behaviour of mor- 
phemes negates haphazard lexical productions, thus, providing an opportunity for appropriate meaning deduction potential of words (Halliday and Matthiessen 2014; Thompson 2014). Examples of a strictly organised morpheme are:
(i) Peacefully
(ii) Enlargement

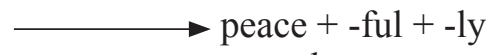
(iii) Fiendishness
(iv) Illegal
(v) Studious
(vi) Godliness
(vii) Establishment

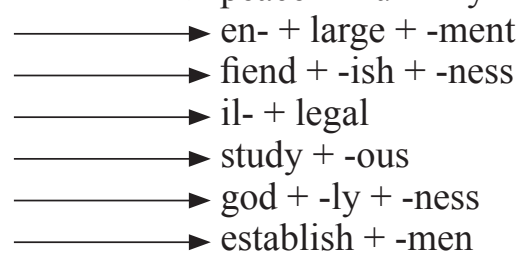

The words in (i) - (vii) project a kind of organisation in a hierarchical order. This refers that inflectional words are constructed in layered ranks (Selkirk 1982; Bauer 2001; Stewart and Vaillette 2001). One can consider the morphological pattern of (i), above, to support the claim.

(i) Peacefully $\longrightarrow\left[\left[[\text { peace }]_{\text {Root }}+- \text { ful }\right]_{\mathrm{DA}}+-\mathrm{ly}\right]_{\mathrm{DA}}$

$D A$ is the mnemonic for derivational affix. The partition classifies the distributional characteristics of the morphemes in peacefully.

Affixes have sub-categorisation characteristics and morphological arrangements (Libben 2003; Aarts and McMahon 2006; Lieber and Štekauer 2011). Aronoff(1976) illustrates the sub-categorisation frame in this way:

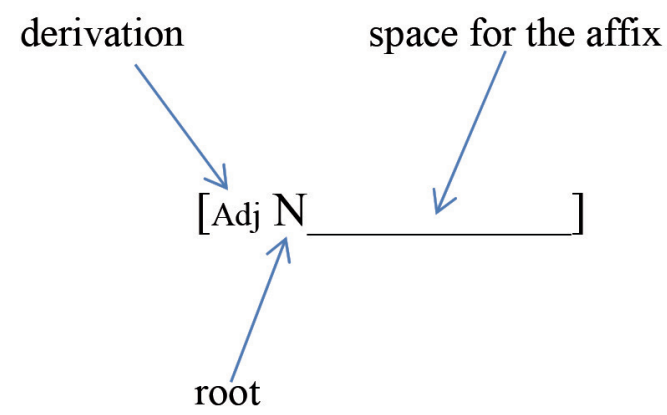

The above formation manifests a new syntactic result (word class) with the new semantic implication (meaning potential). So, the hierarchical morphological organisation of peacefully displays two significant pieces of information. These are morpho-syntactic devices and morpho-semantic elements. The morpho-syntactic indicates the properties of the affix, in which the combination of morphemes to form new word class is exhibited (Vikner and Vikner 2008). The derivational lexical items are:

$$
\begin{aligned}
& {[[\text { peace }]+- \text { ful }] \longrightarrow \text { peaceful }_{\text {Adjective }} \longrightarrow \text { - }} \\
& {[[\text { [peace }]+- \text { ful }] \longrightarrow \text { peacefully }_{\text {Adverb }}}
\end{aligned}
$$


The root/stem peace is a Noun.

The sub-categorisation frame has produced peaceful and peacefully. As the morpho-semantic appears, the terminology pinpoints the meanings of the derivational affixes in the word peacefully such as -ful and -ly (Dalton-Puffer and Plag 2001). On that ground, peaceful=calm; while peacefully = the manner of harmony. Besides the nested parentheses, deployed above to expound the sequence of the hierarchical structures, labelled branching tree, as McGregor (2011) articulates, is an optional form of analysing hierarchical morphological structures of words. For instance, one might represent peacefully thus:

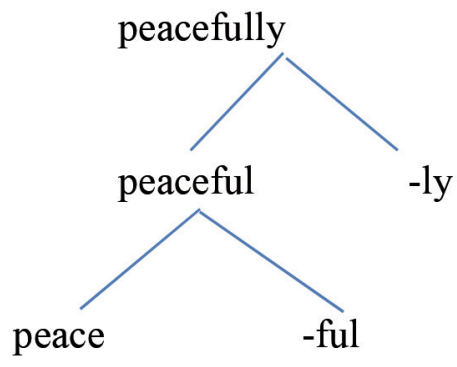

\section{Methodology}

The domain of the data collection was the Punch newspaper between 2010 to 2015 . That period witnessed the proliferation of telecommunications' advertisements in Nigeria, which in the author's point of view, propelled competition in the new business. As I observed, numerous new coinages dominated the advertising space in repetitive forms. However, the study considered about 16 relevant ones each from $M T N^{\circledR}$ and Etisalat ${ }^{\circledR}$. Although there are other telecommunication operators in Nigeria, MTN was the first to come into the market, and Etisalat was the last (Dalamu 2017b, 2017c). Besides that, both MTN and Etisalat seem to be consistent in sensitising the target audience with new constructs. These two reasons are the motivations for considering the novel constructs of MTN and Etisalat among other operators. That choice of 32 lexicons altogether makes the analysis very handy.

The new lexicons, as shown below, are highlighted in bold as functional elements in various clauses. The investigation extracted the entire clauses from the advertising plates so that the operational usages and semantic implications of the new words will be demonstrated to readers. For analysis, the writer further extracted the new linguistic items from the clauses to separately undergo morphological processes and descriptions. As shown in Tables 1 and 2, the study applied the word formation model separately to both MTN and Etisalat items, employing parentheses '[ ]' to analyse the hierarchical morphological structures of compound words. It is in the same way that Figures 2 and 3 assisted in reporting the recurring values of the morphological processes as the copywriters have deployed the morphemes to construct words. Figure 4 illustrates MTN and Etisalat constructs together in order to appreciate the word formation mechanisms that the advertising practitioners utilised to persuade readers. After the comparison, I discuss the new lexemes in relation to linguistics under the 
sub-headings: MTN Communications and Etisalat Communications respectively. CL is an abbreviation of a clause.

\subsection{Data Presentation}

The clauses below are the MTN and Etisalat communications, deployed to excite recipients. The highlighted lexemes indicate the novel constructs in the MTN and Etisalat advertisements.

\subsubsection{MTN communications}

CL 1: MTN Biztime bundles is a part of MTN Enterprising Solutions.

CL 2: MyCuctomer ${ }^{\circledR}$, your smile is worth a thousand 'Thank Yous.'

CL 3: MTN F@astLink

CL 4: MTN Y'ello Bounty. But y'ello days are forever. Look on the $\mathbf{y}^{\prime}$ ello side of life because life is beautiful.

CL 5: The Rider Life train is back with Big SurPrizes! plans.

CL 6: Migrate to HappyLink, FunLink, ProLink, BizLink or SmartLink basic

CL 7: Join the MTN Friendship train as Y'ellofest hits the University of PortHarcourt live!

CL 8: MTN Kulturefest Lisabi

CL 9: You can also send callertunez as gifts to loved ones.

CL 10: Simply text GO to 2010 to join these lucky people!

CL 11: Introducing MTN Lyte Phone

CL 12: Introducing MTN Afrinolly. The latest Nollywood on your phone

CL 13: Y'elloSeasonsPromo. Activate, Recharge and Win

CL 14: MTN Hynet Broadband End of the Year Offer

CL 15: Get MTN4U ...it pays to belong

CL 16: Superfast internet on the go.

\subsubsection{Etisalat communications}

CL 1: Offer opens to all new and existing easystarter and easycliq subscribers.

CL 2: wwwherever you are

CL 3: wwwhenever you wwwant

CL 4: wwwhatever you need

CL 5: get up to $1 \mathrm{~GB}$ freeee!

CL 6: Pick up your easynet data SIM and USB modem at any etisalat experience centre

CL 7: enjoy the easylife \& talk on \& on \& on!

CL 8: 9javaganza, enjoy free weekend calls

CL 9: So pick up your 0809ja phone and start calling! It's your time to talk!

CL 10: we have roots across 9 ja

CL 11: Who will become 9ja's next idol?

CL 12: etisalat, official international partner of FCBARCELONA

CL 13: Ignite ur dream

CL 14: easyblaze, broadband that's finally faster than you 
CL 15: talk longer from your homezone on easy starter

CL 16: easyflex

\subsubsection{Data analysis}

Following Liebner (2004), Almeida and Libben (2005) Tables 1 and 2 below show the analyses of both MTN and Etisalat communicative lexicons. Thus, the deployment of parentheses, as applied in Vikner and Vikner (2008), are used to illustrate the hierarchical morphological structures of MTN and Etisalat innovative constructs.

Table 1. Word formation processes' analysis of MTN communications.

\begin{tabular}{|c|c|c|c|c|c|}
\hline CL & $\begin{array}{c}\text { Novel } \\
\text { Lexicon }\end{array}$ & $\begin{array}{l}\text { Morphological } \\
\text { Description }\end{array}$ & & Basic Lexicon & Formation Type \\
\hline 1 & Biztime & {$[\mathrm{biz}+[$ time $]]$} & $\longrightarrow$ & business time & Compounding \\
\hline $2 \mathrm{a}$ & Mycustomer & {$[$ my $+[$ customer $]]$} & $\longrightarrow$ & my customer & Compounding \\
\hline $2 b$ & Thank Yous & {$[[$ thank + you $]+-s]$} & $\longrightarrow$ & you '-s' & Deviant \\
\hline 3 & F@astLink & {$[\mathrm{f} @ \mathrm{st}+[$ link $]]$} & $\longrightarrow$ & fast link & Compounding \\
\hline 4 & SurPrizes & {$[[$ sur- $+[$ prize $]+-s]$} & $\longrightarrow$ & surprise prizes & Blending \\
\hline $5 \mathrm{a}$ & HappyLink & {$[$ happy $+[$ link $]]$} & $\longrightarrow$ & happy link & Compounding \\
\hline $5 b$ & FunLink & {$[$ fun $+[$ link $]]$} & $\longrightarrow$ & fun link & Compounding \\
\hline $5 c$ & ProLink & {$[$ pro- $+[$ link $]]$} & $\longrightarrow$ & professional link & Compounding \\
\hline $5 d$ & BizLink & {$[\mathrm{biz}+[$ link $]]$} & $\longrightarrow$ & business link & Compounding \\
\hline $5 e$ & SmartLink & {$[$ smart $+[$ link $]]$} & $\longrightarrow$ & smart link & Compounding \\
\hline 6 & Y'ello & {$[y-]+[$-ello $]$} & $\longrightarrow$ & yellow hello & Blending \\
\hline 7 & y'ellofest & $[y-]+[$-ello $]+[$-fest $]]$ & $\longrightarrow$ & $\begin{array}{l}\text { yellow hello } \\
\text { festival }\end{array}$ & Compounding \\
\hline 8 & Kulturefest & $[$ Kulture + [-fest $]]$ & $\longrightarrow$ & culture festival & Compounding \\
\hline 9 & Callertunez & $[[[$ call $]+$-er $]+$ tune $]+z]$ & $\longrightarrow$ & caller tunes & Compounding \\
\hline 10 & text & text & $\longrightarrow$ & text & Conversion \\
\hline 11 & lyte & lyte & $\longrightarrow$ & light & Deviant \\
\hline 12 & Afrinolly & [afri- + [-nolly]] & $\longrightarrow$ & Africa nollywood & Blending \\
\hline 13 & $\begin{array}{l}\text { Y'elloSeasons } \\
\text { Promo }\end{array}$ & $\begin{array}{l}{[\mathrm{y}-]+[\text {-ello }]+[[\text { season }]} \\
+\mathrm{s}]+[\text { promo }]\end{array}$ & $\longrightarrow$ & $\begin{array}{l}\text { yellow hello } \\
\text { seasons promotion }\end{array}$ & Compounding \\
\hline 14 & Hynet & {$[$ hy- $+[$-net $]]$} & $\longrightarrow$ & high Internet & Deviant \\
\hline 15 & MTN4U & {$[[[\mathrm{MTN}]+4]+\mathrm{U}]$} & $\longrightarrow$ & MTN for you & Alphanumeric \\
\hline 16 & Superfast & {$[$ super- $+[$ fast $]]$} & $\longrightarrow$ & super fast & Compounding \\
\hline
\end{tabular}


Table 2. Word formation processes' analysis of Etisalat communications.

\begin{tabular}{|c|c|c|c|c|c|}
\hline CL & $\begin{array}{l}\text { Novel } \\
\text { Lexicon }\end{array}$ & $\begin{array}{l}\text { Morphological } \\
\text { Description }\end{array}$ & & Basic Lexicon & Formation Type \\
\hline 1 & wwwherever & $[$ www $+[$ where $]+$ ever $]]$ & $\longrightarrow$ & $\begin{array}{l}\text { world wide web } \\
\text { wherever }\end{array}$ & Compounding \\
\hline 2 & wwwhenever & $[$ www $+[$ when $]+$ ever $]]$ & $\longrightarrow$ & $\begin{array}{l}\text { world wide web } \\
\text { whenever }\end{array}$ & Compounding \\
\hline 3 & wwwant & {$[w w w+[w a n t]$} & $\longrightarrow$ & $\begin{array}{l}\text { world wide web } \\
\text { want }\end{array}$ & Compounding \\
\hline 4 & wwwhatever & $[w w w+[$ what $]+$ ever $]]$ & $\longrightarrow$ & $\begin{array}{l}\text { world wide web } \\
\text { whatever }\end{array}$ & Compounding \\
\hline 5 & Freeeee & {$[[$ free $]+$ eee $]$} & $\longrightarrow$ & free & Deviant \\
\hline 6 & Easynet & $[$ easy + -net $]]$ & $\longrightarrow$ & easy Internet & Compounding \\
\hline $7 \mathrm{a}$ & Easystarter & $[$ easy $+[$ start $]+$ er $]]$ & $\longrightarrow$ & easy starter & Compounding \\
\hline $7 b$ & Easycliq & {$[$ easy $+[$ cliq $]]$} & $\longrightarrow$ & easy click & Compounding \\
\hline 8 & 9javaganza & {$[9 \mathrm{ja}+[$-vaganza $]]$} & $\longrightarrow$ & $\begin{array}{l}\text { Nigeria } \\
\text { extravaganza }\end{array}$ & Alphanumeric \\
\hline 9 & 0809ja & {$[080+[9 \mathrm{ja}]]$} & $\longrightarrow$ & 080 Nigeria & Alphanumeric \\
\hline 10 & $9 \mathrm{ja}$ & $9 \mathrm{ja}$ & $\longrightarrow$ & Nigera & Alphanumeric \\
\hline 11 & 9ja's & {$[[9 \mathrm{ja}]+-\mathrm{s}]$} & $\longrightarrow$ & Nigerian's & Alphanumeric \\
\hline 12 & FCBarcelona & {$[\mathrm{f}+[\mathrm{c}+[$ Barcelona $]]$} & $\longrightarrow$ & $\begin{array}{l}\text { football club } \\
\text { Barcelona }\end{array}$ & Compounding \\
\hline 13 & ur & ur & $\longrightarrow$ & your & Clipping \\
\hline 14 & Easyblaze & [easy + blaze $]$ & $\longrightarrow$ & easy blaze & Compounding \\
\hline 15 & Homezone & {$[$ home $+[$ zone $]]$} & $\longrightarrow$ & home zone & Compounding \\
\hline 16 & Easyflex & {$[$ easy $+[$ flex-]] } & $\longrightarrow$ & easy flexible & Compounding \\
\hline
\end{tabular}

Tables 1 and 2 above do not only describe the morphological processes of the newly formed words of the MTN and Etisalat, but the tables also show the root words, influenced to produce the novel items. The study adopts the salient terms such as alphanumeric, deviant and compounding in order to realise certain formations that are 'linguistic unorthodoxy' (Leech 1966: 175). This is on the ground that some formations attract two or more morphological processes. Among others, alphanumeric refers to a combination of numbers and letters; deviant points to formations that are critically arbitrary; and compounding is an appreciation of a combination of morphemic elements to produce a word. Some of the morphemes operate hierarchical structures. The terminology, deviant, represents some formations that appear as an aberration in its absoluteness in linguistics. Nonetheless, the study translates Tables 2 and 3 to tables and graphs as means of accounting for the values of the word formation processes. 


\section{Results}

Tables and graphs in Figures 2 and 3, paralleled with Hay (2001), Leech, Rayson and Wilson (2001) and Dalamu (2017a, 2018a), display the digitised values of the word formation processes. Figure 4 juxtaposes and measures the word formation models of MTN and Etisalat adverts.

\begin{tabular}{|l|l|l|}
\hline S/N & Formation Process & MTN \\
\hline 1 & Blending & 3 \\
\hline 2 & Borrowing & 0 \\
\hline 3 & Coinage & 0 \\
\hline 4 & Compounding & 13 \\
\hline 5 & Acronym & 0 \\
\hline 6 & Conversion & 1 \\
\hline 7 & Calque & 0 \\
\hline 8 & Clipping & 0 \\
\hline 9 & Backformation & 0 \\
\hline 10 & Deviant & 3 \\
\hline 11 & Alphanumeric & 1 \\
\hline
\end{tabular}

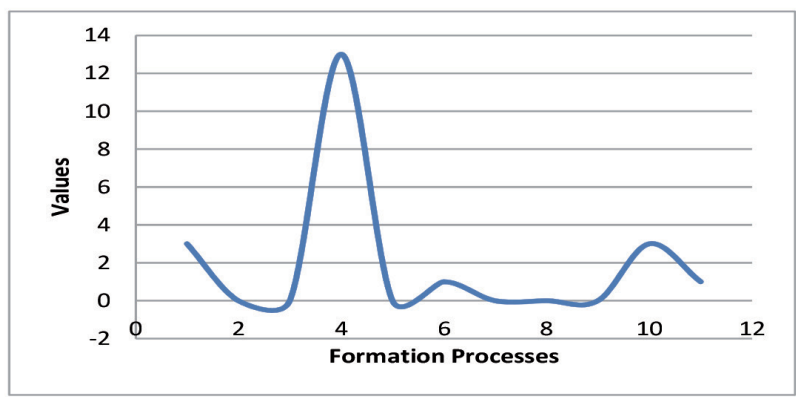

Figure 2. Digitized values of MTN word formation processes.

The calibration in Figure 2 indicates that $M T N$ employs the method of compounding so well in the formation. Compounding, as a procedure, records 13 points, positioning the concept as the most utilised device by the MTN advertising experts. Blending and deviant constructions respectively recur to produce three points. However, derivation and alphanumeric word formation methods score one point each. By implication, MTN copywriters enjoy the production of new words in compounding structures to form novel words.

\begin{tabular}{|l|l|l|}
\hline S/N & Formation Process & Etisalat \\
\hline 1 & Blending & 0 \\
\hline 2 & Borrowing & 0 \\
\hline 3 & Coinage & 0 \\
\hline 4 & Compounding & 11 \\
\hline 5 & Acronym & 0 \\
\hline 6 & Conversion & 0 \\
\hline 7 & Calque & 0 \\
\hline 8 & Clipping & 1 \\
\hline 9 & Backformation & 0 \\
\hline 10 & Deviant & 1 \\
\hline 11 & Alphanumeric & 4 \\
\hline
\end{tabular}

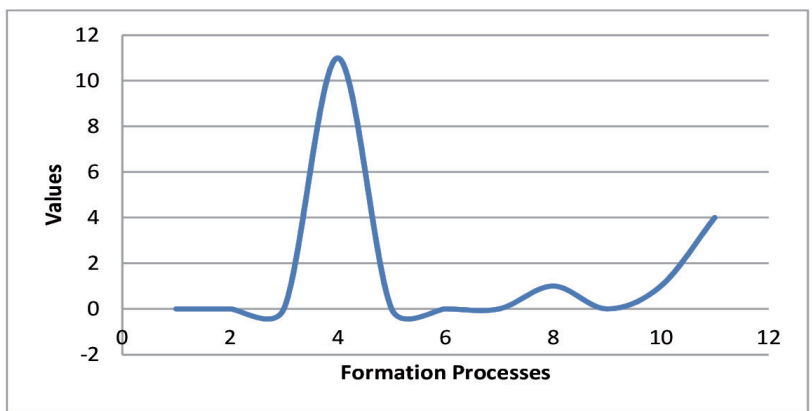

Figure 3. Digitized values of Etisalat word formation processes.

As exhibited in Figure 3, compounding yields 11 points, approaching the most appreciated in the Etisalat advertising word formation processes. Next to that is the alphanumeric code that scores four points. The digitised structure demonstrates clipping and different elements, operating less in the formation. This is because clipping and deviant formation potencies record one point each on the graph. Therefore, Fig- 
ure 3 refers that compounding and alphanumeric codes are regular procedures of word formation systems in Etisalat communications.

\begin{tabular}{|l|l|l|l|}
\hline S/N & Formation Process & MTN & Etisalat \\
\hline 2 & Blending & 3 & 0 \\
\hline 3 & Borrowing & 0 & 0 \\
\hline 4 & Coinage & 0 & 0 \\
\hline 5 & Compounding & 13 & 11 \\
\hline 6 & Acronym & 0 & 0 \\
\hline 7 & Conversion & 1 & 0 \\
\hline 8 & Calque & 0 & 0 \\
\hline 9 & Clipping & 0 & 1 \\
\hline 10 & Backformation & 0 & 0 \\
\hline 11 & Deviant & 3 & 1 \\
\hline 13 & Alphanumeric & 1 & 4 \\
\hline
\end{tabular}

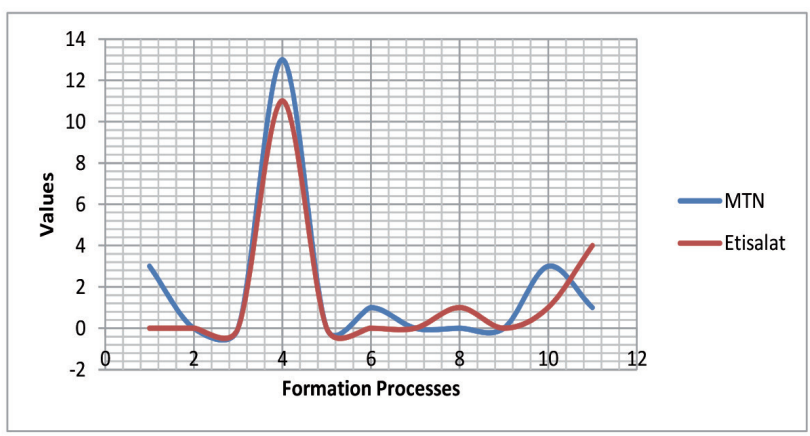

Figure 4. MTN and Etisalat word formation processes' juxtaposition.

The comparison of MTN and Etisalat in Figure 4 reveals that on the one hand, the telecommunications operators produce novel lexicons more often than not through compounding procedures (Adams 2001). On the other hand, however, MTN and Etisalat differ in the employment of blending, deviant and alphanumeric facilities. MTN creates more words by blending morphemes and deviating from norms than Etisalat; whereas Etisalat makes use of alphanumeric morphemes in the formation of new lexemes. Apart from the effective strategy that motivates MTN and Etisalat to create these constructs, observations show that the novel lexicons in one way or another contribute to (i) language development and (ii) linguistic descriptivism. One could also add that the newness of the words seems to have the capacity to excite the public to consume.

\section{Discussion}

One thing that distinguishes advertising from many writings is its creative style. The burden of attracting the public to the message intended seems a vehicle for creativity as experienced in advertising communications. Thus, the poetic license of advertising practitioners is a product of imagination as a means of inspiring the target audience, who are sometimes recalcitrant, to the communications (Cook 2001). Freedom of creative rules, as Leech (1966) emphasises, is a necessary condition for successes in the advertising industry. It is in that respect that $M T N^{\mathbb{B}}$ and Etisalat ${ }^{\mathbb{R}}$ advertisements deploy certain informative and innovative lexicons in suitable word classes to persuade recipients. The explanation on the novel words concentrates on the morphological descriptions concerning meaning potential as well as the parameters that facilitate the formation procedures.

\subsection{MTN communications}

The biztime lexeme of MTN is a combination of biz and time. Biz is slang, representing a short form of business as a commercial enterprise. It is an occupation of an 
individual or a firm, or the volume of dealings-cum-transactions between one person or the other. As deployed in CL 1, it is suggestible that biz implies the management of an excellent commercial product in a very prompt manner. That could be the reason for the production of biztime as a compound from two different entities of biz and time with a morphological hierarchy. The sub-categorisation frame, as exhibited in Table 1, pinpoints time as the root and biz as a qualifier-morpheme attached to the root as an affix. Time catalyses subscribers, indicating the appropriate moment for them to transact business with MTN through the purchase of biztime bundles as a package of communication. In that vein, MyCustomer ${ }^{\circledR}$ in CL $2 \mathrm{a}$ is an associate of two distinct words of my and customer, where the advertiser joins my as affix to customer, the root. MyCustomer as a compound word goes beyond being a lexeme to being a sellable product on its own. This is on the ground that MyCustomer is a registered business facility of $M T N$, as 'annotated' with an implicit ' $₫$.' In this case, the registered coronet poses a constraint for other telecommunications operators to use the construct in such combined appearance. MyCustomer, as a registered entity has attracted a sort of legal backing in the business domain in Nigeria. It is solely a product and property of MTN.

The lexicon in CL 2b, that is, Thank yous is very striking. It is not because of its service as a minor clause but Thank You has its fulfilment in the inflectional morphemic bound of $-s$. As a result of the unusual combination that produces a zero-derivation, the analyst could classify Thank Yous as being deviant in the word formation process. This linguistic, behavioural drift of the MTN advertiser could be fastened to what Wimsatt and Beardsley (1954: 21) call intentional fallacy.

F@atLink in CL 3 enjoys a compounding system that entices the Internet concept of@alongside with two separate words of fast and link. Link is the root that is united with fast as a morpheme to produce the compound structure F@atLink. Furthermore, what occurs in the formation process is the substitution vitality, where the symbol@ takes the position of $a$ in fast. One might quickly say that the substitution of @ for $a$ performs different functions. Fast, operating with $a$ does not accomplish the message intended as operating with@. The reason is that @ de-notes at in computerisation/Internet domains, while $a$ is a letter of the alphabet. Therefore, F@ast with an intrusion of @ points recipients to the Internet opera-tions in MTN.F@stLink is an unusual rapidity that consumers will experience when using the MTN Internet bundle. The bundle, from the perspective of $M T N$, does not only connect a subscriber to Internet sites, but it does also protect data wastages which in-turn saves costs.

An additional perspective of the creativity is that there is a linking relationship between what is to communicate to the audience and the computer. The advertisement is about MTN, the personal computer (PC) and the Internet. At a flash, looking at the wordF@stLink signals@ to readers, which is a common thing on the keyboard of a computer. The digit@ is an integral element in the email addresses across the globe. When an individual communicates through the Internet to friends and institution, the@ digit is a key element. The MTN advertiser connects linguistic elements of letters with a computer sign to fascinate customers. The element@ @erforms two functional purposes in the word formation: (i) $a$ is the first letter of the English alphabet; and (ii) at in the Internet domain.

The elements of surprise and prizes have undergone a blending operation to produce SurPrizes. The exercise takes sur- away from surprise as a semi-morpheme and 
combines it with prizes to yield SurPrizes in CL 4. However, the inflectional morpheme $-s$ is added to prize, producing the plural form, prizes. Then, observations show that SurPrizes is a derivative of surprise, prize and -s. One, surprise is an indicator of the feeling that something unexpected happens from MTN to consumers. Two, the unexpected package of communication is not only inductive but also rewarding in the Nigerian telecommunications industry. The 'inflectional' blending has one goal: it is to charm the target audience to patronise MTN products and services.

The compounding words of HappyLink, FunLink, ProLink, BizLink and SmartLink in CLs 5a to 5e focus on the same thing on the Internet. Link serves as the interface between subscribers and enthusiasm for surfing the Internet websites. Structurally, HappyLink, FunLink, ProLink, BizLink and SmartLink have their 'prime factor' as Link, being the root of all the other linguistic constituents. As a result of that characteristic, Link has different lexemic partnerships for the attainment of the messages intended. The partners are: Happy - having a feeling of favourable fortune arising from the consumer's consciousness; and Fun - amusing and enjoyable activity, usually deployed as an informal communicative device. Another associate of Link is Pro - a reference to expertise in a particular field of endeavour. Pro- is a semi-morpheme fragmented from the lexicon professional. The shortening, Pro-, aims at influencing people, who are specialists in certain fields. ProLink, in the point of view of MTN, is capable of assisting users in providing Internet solutions. Other structures with Link are Biz, a pointer to business; and Smart, which exhibits intelligent behaviour, social cleverness and intellectual prowess. As Biz is slang and a prefix, supporting Link; so also is Smart operating as a qualifier to Link. These wits, one could suggest, transcend the recipients of the communication beyond the reading of words for pleasure to the business world, where MTN invites readers to become loyal subscribers of the campaigned Internet services.

Y'ello is formed arbitrarily from two words, that is, yellow and hello. Y'ello might somehow be out of a linguistic context. The reason is that, except one is very close to MTN as a company, the structure of Y'ello will be difficult to decipher. This combination is generated from two perspectives: yellow is the branded colour of MTN telecommunications; hello is the starting point of a telephone conversation. That is, a point of departure for telephone interlocutors. In this regard, I consider the punctuated $y$-as the semi-prefix and the chopped up -ello as the semi-root. These explanations are motivators that connect yellow and hello together to form Y'ello in the MTN language choice. Notwithstanding the arbitrariness of this combination shown through the apostrophe ['] that separates $Y$ and $e$, the study considers this formation as a perfect blending. The formation demonstrates the poetic license of publicists (Xhignesse 2016).

The copywriter deduces Y'ellofest from the orientation that Y'ello creates. Yellow, hello and festival manifest the seemingly compounding lexeme of Y'ellofest. The labelling of the combination in such manner is because the formation system attracts blending, shortening and compounding at a stretch. Having mentioned earlier that Y'ello is a product of yellow and hello, -fest is a reductive manifestation of festival, that the author can technically refer to as a kind of semi-suffix. In this case, Y'ellofest is a conceptual terminology that MTN has created in order to associate with social events in Nigerian society. CL 7 exhibits the claim by demonstrating the University of Port Harcourt where Y'ellofest is staged. 
MTN seemingly displays a similar compass of Y'ellofest to realise the compounding formation of Kulturefest.Kulturefest as the joining of culture to festival is a mythological affiliation with the unique Lisabi celebration in Abeokuta, Nigeria. Very salient in the compounding construct is the adoption of the voiceless velar stop [ $\mathrm{k}$ ] as a replacement for the grapheme $c$ (Ladefoged 1982). So, it seems that as MTN deploys the verbal entity of Y'ello to promote itself, it is in the same way that the telecommunications operator commercialises Y'ellofest and Kulturefest (Horn 2010) as resources of persuading the audience. Hence, I might reiterate that the fragmented -fest operates as a semi-suffix, indicating festival.

Another linguistic structure functioning in the sphere of compounding is callertunez. Callertunez portrays a similar idea with Kulturefest. While Kulturefest is a compounding system with $[k]$ velarised phoneme at its starting point, callertunez enjoys an association with voiced alveolar fricative $[z]$, supporting the item in the front (Gimson 1985). Nonetheless, $-z$ is a straightforward graphic representation in the formation, as the plural marker operates as a voiced element in the callertunez construction. In the hierarchical morphological organisation, call is the root that connects the inflectional suffix -er; whereas the adapted $-z$ is the suffix of tune. Moreover, the propagation of the $[z]$ fricative emphasises the musical melody of the tunes that interactants enjoy while talking through their telephones. The harmony that good songs produce serves as a worthwhile facility of convincing the readers of the importance of their sincere patronage. Callertunez is inflectional in two different dimensions. The first is the joining of the nominal morpheme -er to the lexical morpheme, call. The second as articulated in CL 9 is the combination of tune, and the advertiser's morpheme voiced alveolar fricative [z] (though a phoneme in the real sense of linguistic classifications).

Language changes over time. One of the numerous ways in which this change takes place is through the process of category shift. Category shift in word classes is a process in which a word that originally belonged to a particular word class gradually begins to be used as another word class. This process occurs naturally among speakers of English (Okoro 2006). Linguistically, text was a noun word in its grammatical word class. Using text as a verb is a function ascribed to it newly for the convenience of conversational norms in the telecommunications' business environment. The paradigm shift tagged category shift has occurred as the usage of text as a verb persists. The consistent usage has turned text to have other verbal elements such as texts, texted, texting. These elements, one can suggest, are purely mobile telephony constructs. The free morpheme text enjoys a functional shift from a nominal lexeme to a verbal device. The new communicative role positions text as being morphologically zero derivation. The reality of the emerging trends of the functions of language in Nigeria as well as the global contexts confirms the pervasive use of English (Jowitt 1991; Bamgbose, Banjo and Thomas 1995). In the most critical aspects of our national and international programs, ranging from educational, administrative, economic, diplomatic, technological, scientific to communication activities, English changes overtime (Akere 2004; Dadzie and Awonusi 2004; Kachru 2017).

From the remarks above, the functions that advertisers employ propel these professionals to go haywire in the manner that they form words. The context of dual skills of creativity and distraction has given rise to the emerging trends of experiencing novel coinages in advertising communications. In Okoro's (2008) argument, 
such deployment might sometimes be completely erroneous. The creativity built into advertising makes it thick in text and stick to the heart of readers. The primary mission of advertising is to try to get the audience to think of the product in question in a particular direction. A good advertisement must artfully draw the attention of the consumers to itself. That is why Myers (1994) asserts that a copywriter ensures that the text is strongly distinguished and also indulged in a use of language in a way that stands out against ordinary usages. So, pervasive deployment of language is a style in the advertising realm.

Lyte is a deviant construct from light. The copywriter displays the concept of poetic license to excite consumers. Apart from the textual reformation, light in its natural standing is an independent morpheme. The original lexeme, light, as utilised in CL 11, is very ambiguous. Light exhibits different levels of linguistic meaning potential, and as such the terminology produces multiple meanings. Light illuminates consumers to establish that $M T N$ services are unencumbered, but they are rather clear of any impediments and swiftly active in communication exercises. From a perspective of hardware, light refers consumers to telephones of MTN as light-weighted devices. This way, subscribers, MTN assures, have no worries concerning both MTN services and products.

The combinatory nature of Afrinolly is a different kind of blending. In a sense, blending might take the point of departure of a word and join it to the end of the other word. The blending of Afrinolly takes the beginning of Africa (Afri-) and joins it to the beginning of Nollywood (Nolly-). Such sense projects Afri- and nolly- as punctuated elements of Africa and Nollywood. So, nolly- is the root or stem; while Afri-is the prefix in the affixation mechanism. Specifically, Nollywood is a replica of the American, Los Angeles, Hollywood as well as Bollywood in Mumbai, India. The replica is owing to the principles of the motion picture industry in America and India that Nigeria has decided to emulate. By implication, MTN extends the concept-cum-principle of the 'woodism' to the entire African continent. That decision has given rise to the lexicon, Afrinolly.

MTN has customised Y'ello as its property as earlier stated. The tendency influences the compounding function of Y'elloSeasonsPromo. Y'elloSeasonsPromo is an intersection of four distinct lexicons to produce a single one. These are yellow, hello, seasons and promotion. The angle of morphological inclination of those organs rests on blending (yellow + hello), root and inflexion (season $+s$ ), and clipping (promotion $\rightarrow$ promo). These formation exercises have produced yellow, hello, seasons and promotion, nevertheless, with season as the root with a pluralised $-s$ morphemic inflexion. Observations exhibit -tion as another suffix of a referential morpheme promote. As a result of these combinatory possibilities, two bound morphemes - seasons and promotion - operate in the compounding word formation process. The point that MTN makes with Y'elloSeasonsPromo is that the marketing gimmick of this kind comes once in a while. This is a clear ploy to heighten the morale of the public to benefit from the exercise now or in the nearest future.

CL 14 postulates a deviant construct of hynet. This is because hynet is an assumption of blending from high and Internet. However, $h i$ - is converted to $h y$ - to achieve a persuasive mission perhaps of differentiation. -Net is an abstraction of Internet. Plausibly, the combination of hy- and -net produces hynet as a reference to the elevated status that MTN Internet provisions probably have above the other competitors. Therefore, hynet as a service seduces subscribers to patronise the package. In 
this likely hierarchical morphological class, -net, a fragmented morpheme of Internet is the root, having hy-representing high as its semi-suffix.

The alphanumeric code MTN4U in clause 15 accommodates MTN, 4 and $U$. MTN is an acronym for Mobile Telephone Network (Wikipedia 2016). 4 is a digit of the number and $U$ represents you. Despite that $M T N 4 U$ is alphanumerically organised, the sequence of the structure is an absorption of an acronym (M. T. N.), compounding $(M T N+4+y o u)$, and clipping, $(y o u \rightarrow u)$. In a technical case, one might suggest that $M T N$ functions as the root of the formation with 4 and $U$ playing the role of 'alphanumeric' and 'clipped' suffixes. The offering of MTN4U augments easy accessibility of subscribers to $M T N$ products and services. This is because when the information of advertising is burdensome, recipients might neither consume the message nor patronise the advertised product.

Super and fast are morphemes that produce Superfast in the domain of the compounding process of word formation, deployed in CL 16. The hierarchical formation concept reveals fast as the root with super- as the prefix. Super means excellent quality of service while fast indicates firmness, fortification and stability. In that regard, the semantic realisation of Superfast decorates the MTN Internet as discharging wonderful services in steadfast manners. Moreover, every user of the Internet loves to do things on websites without wasting much time; as the advertiser emphasises, that is a probable motivation for the construct of MTN Superfast.

\subsection{Etisalat communications}

The author might follow the path of Leech (1966: 175) to reiterate that there is often no word on the mind of an advertising specialist than creativity. The individual tends to work creatively on creative campaigns. When a copywriter is not engaged in creative planning, as Leech asserts, perhaps, the individual is thinking about creative ideas. The major task before the Etisalat advertiser is to seduce and capture the audience. For the advertiser to be consistently maintaining the relationship with the audience, the language choices must be loaded with creative weapons and imaginative skills (Bolinger 1987). Repetition of advertising paralinguistic and linguistic materials alone sometimes might not help matters. Then, creativity becomes a necessary tool of persuasion (Packard 2007). Based on this, the Etisalat advertiser is prone to logical/illogical creativity and imagination that are linguistically interpretable or mutilated.

The $w w w$ structure positions CLs 1 to 4 of the Etisalat advertisements as texts in relationship with the Internet. The merger of $w w w$ with the $w h$ - elements answers the questions of where?, when?, and what? in association with the desire (expressed as want) of subscribers. The fusion of $w w w$ elements goes along with the $w h$ - questions thus: (i) $w w w+$ where + ever to produce wwwherever; (ii) $w w w+w h e n+$ ever) to produce wwwhenever; and (iii) $w w w+$ what + ever to produce wwwhatever. Want is not a family of $w h$ - yet $w w w$ forms an alliance with want to produce wwwant. All the four lexicons are products of compounding formation processes (Booij and van Marle 2002; Lieber 2004). The www is an acronym of World Wide Web which has an affiliation with the linguistic organs mentioned above. Apart from wwwant that has two forms of morphemic combinations of an acronym $w w w$ and lexical item want, all the others have three morphemes fused to produce a lexeme each. That is, the acronym $w w w$, lexical devices where, when and what, and the suffix ever. By seman- 
tic implication, where is a marker of adverbial of place or location; when is a marker of adverbial of time; and what interrogates a circumstance of specification in terms of identity, quality and quantity. Want refers to the need of a reader. In all these, Etisalat utilises the novel compounding constructs to open up a trouble-free way for subscribers to access the Internet. The claims of the 'coinages' indicate that the Internet services that Etisalat provides are multi-functional.

In CL 5, Etisalat encourages subscribers to travel the world nights and weekends without charges and to get up to $1 \mathrm{~GB}$ freeeee Internet data. One could observe the structural device in the multiple recurrences of the letter $e$ about three extra times. The -eee operates as a morpheme, making it a suffix to the lexical component free. Apart from the technical production aspect, it is nice to argue that anything that is given free does not attract any payment. In this case, there is a gratis offer that is obtainable and enjoyable only when a subscriber recharges the Etisalat line. It means that the free recharge campaign of Etisalat is not a gift at all but a bait. The exhibition of free is a contradiction in the side of the Etisalat advertiser. Strange though, the poetic license of advertising practitioners, as a reference point, has made it a right to feature free as freeeeee perhaps for a reason of emphasis. The formation is alarming. Apart from advertising, this linguistic aberration of $e$ recurring five times as a vowel in a word at a go is quite unacceptable in English either in Nigeria or outside it. Free is free anywhere in the world, but to the Etisalat advertiser, there is a free world in which the professional's linguistic choices are exercised.

The word formation process, which easynet, easystarter and easycliq have undergone, is compounding (Hammond and Noonan 1988) as shown in clauses 6, 7a and $7 \mathrm{~b}$. Easynet is compounding as well as adopting clipping in the exercise. This is because easy is a morpheme connected to -net, an abstraction from the Internet. The compounding nature of easystarter does not only join easy, prefix, with start, root; it also employs the nominal morpheme of -er to support the formation. The invitation is to nominalise easystart as a human entity, like this; the production of easystarter becomes imperative. The cliq in the compounding system of easycliq illustrates that this formation is a bit dissimilar from the rest. Easycliq follows the compounding procedure with easy as the prefix and cliq as the root (Jensen 1990; Haspelmath 2002). It is worth mentioning that Cliq is a derivative of click. The consonantal realisation of $q$ and $c k$ in the phonetic field is $[k]$. The copywriter employs the voiceless velar stop [k] (O'Connor 1973) to replace the $c k$. Nonetheless, the grapheme $q$ that sounds as $[k]$ displaces $c k$ in the formation. This is the essence of using cliq instead of click. Consequently, easy means comfort that harnesses freedom while click in its real sense is an act of pressing a button on a computer mouse to navigate the software. The advertising expert creates a form of effortless operations for subscribers regarding the usages of Etisalat Internet services.

The items in clauses 8, 9, 10 and 11 are structures of a kind. This is on the basis that 9ja is a common morphemic denominator in all the constructs. There are 9javaganza, 0809ja, 9ja and 9ja's. Although the words use alphanumeric codes (Dalamu 2018a), the constructs still dispense one or two differences in the formations. Although 9javaganza is a combination of $9+-j a+-v a g a n z a$, the hierarchical morphological structure realises punctuated -vaganza as the root that attracts 9ja as the prefix. If the word has been written as extravaganza in the advertisement, the root would have been extravagance. In the current arrangement, 9 is a digital value, $-j a$ is from a graphemic abstraction of Nigeria; as -vaganza is to extravaganza. Extravaganza 
displays a fantastic conduct of Etisalat to Nigerian subscribers regarding superfluity of recharge cards. Being a business enterprise, it could be erroneous for one to think that Etisalat's excessive lexical demonstration amounts to a waste of resources. To the analyst, the textual expression of prodigality is pretentious, which cannot negatively affect the financial management of the firm.

The crux of the element, that is, 9ja, is very impressive. As earlier mentioned, 9ja refers to Nigeria. However, $9=N i$ - while $-j a=$-geria. The realisations are slangy terms but the usages spread in the Diaspora like fire. To a large extent, 9ja was officially unfolded, propagated and popularised in the Super Eagles' (Nigerian football team's) jerseys in the just concluded 2018 World Cup held in Russia. Linguistically, the -ja deployment is just a matter of conversational convenience. That perspective seems to influence users to deploy the combination of $[j]$ - palatal approximant with [a] - open central tense vowel (Adetugbo 1997) to replace and realise -geria. The operator that is foresighted takes advantage of the social phenomena of semivowel $[j]$ and low central tense vowel [a] to influence the decision of subscribers concerning Etisalat services. The investigation further locates the fraternisation of Etisalat with 9ja through the inflexion of the possessive $-s$ as illustrated in CL 11. These various formations with 9ja have positioned 0809ja as a symbol of Etisalat in the Nigerian business setting. 0809 is the first four digits of Etisalat numbers. In sum, the functional domains of 9ja in CLs 9, 10 and 11 are: 9ja as in CL 9 is the root with 080 as the prefix; whereas CL 10 depicts 9ja as a lexical item; and 9ja as the root in CL 11 attracts a suffix $-s$ to indicate a form of the ownership culture. Indirectly, such utilisation has promoted and characterised 9ja as an acceptable word in the Nigerian social milieu, which can easily possibly influence inflectional partnerships.

FCBarcelona in CL 12 has a morphological appreciation of acronym and compounding (Payne 2006; Lieber and Štekauer 2011), as examined, for example, in CL 1. Structural details reveal that $f$ - and $c$ - are morphemes in the prefix hemisphere; Barcelona is the root. FC is an acronym of Football Club. Barcelona, the name of an autonomous capital city in Spain is joined to FC to achieve the construct, FCBarcelona, as illustrated above. Historical verifications report that the original name of the club is Futbol Club Barcelona with a short form as FCB. Being a Spanish club at Camp Nu, FCB is in La Liga. Based on the Forbes and Deloitte evaluations, $F C B$ 's financial worth as a registered association is about US\$1billion as of 2016. With a crop of players such as Xavi, Iniesta, Messi, Eto'o, Ronaldinho and Puyol, it is remarkable that Lionel Messi is the FCB's all-time top scorer under the management of Josep Maria Bartomeu, the current club president (Shubert 1990; Murray 1998; Roy 2001; King 2003; Ball 2003; Eaude 2008; Ferrand and McCarthy 2008; DeSantis 2016; Deloitte UK 2016). Besides the formation technique that Etisalat assigned to Barcelona Football Club, the union could sensitise the audience to patronise Etisalat products. The fundamental point is that many Nigerians love the $F C B$ 's pedigree and associate with the club. Etisalat seizes that opportunity as a platform to campaign goods and services.

Ur, as indicated in CL 13, has undergone a clipping system (Stockwell and Minkova 2001; Katamba and Stonham 2006; Sugioka 2011). Ur is a shortening form of your that the telecommunications industry sells to the Nigerian people. Ur eases communication etiquettes because the fragmented linguistic component (Carter and Nash 2013) conserves the time of interactants most especially in the typing of texts in telephones. The convenience and time saving might have enhanced the apprecia- 
tion of ur among the English language users. $U r$ as a representative of your, a possessive as well as an adjective, indicates the ownership of an object. In addition, at the same time, $u r$ is a conveyor of mutual knowledge and familiarity with a modified nominal identity to readers.

The production of easyblaze in CL 14 is compounding. The free lexical morphemes of easy and blaze unite in the formation system to achieve a compounding product (Matthew 1974). Structural indications pinpoint easy as the root and blaze as the suffix because easy has almost become Etisalat's marketing registered label or brand. Easy is a kind of liberty that an individual has to function in an activity requiring little skills. Blaze refers to a fast-burning and high-visibility functional material. This could be associated with a fire that discharges at high intensity. In another sense, one might connect blaze to an active display of quality in all its ramifications. Constructing and propagating easyblaze as a characteristic of an Etisalat's Internet package seems a welcoming idea. Hence, the communication visualises the Internet package as a tool of time-saving. In a way, the public may love to associate with the term because of the features related to its campaigns.

The combination of home and zone as lexical morphemes yield homezone as a product. In the compounding formation (Ruzaite 2012), I recognise home as the prefix and zone as the root for home modifies zone in the affixation. Home is a dwelling place of personal abode. It is a place where one raises a family. Such traits characterise home in CL 15 as being domestic and a personal region of affection. The analyst could say that zone is also connected to a region in the sense that zone is a probable distinguished area with certain features possessing parallel intersection with an individual. As a result of that picture, the Etisalat's homezone projects both comfort and favour for subscribers. The projection is a bit fascinating because Etisalat hides under the auspices of making people comfortable to market the advertised product.

In CL 16, the copywriter achieves the fabrication of easyflex through a word formation system of compounding and as such easy, the root, and flex-, the semi-suffix, unite as an indivisible entity for the easyflex product. Easy is a lexical morpheme in the free status (Bauer and Huddleston 2002); nevertheless, flex is a reducible form of flexible. The nature of the reducibility exhibits the 'drama' that advertising professional can perform with word formation methods. Word play in the workshop of advertising practitioners can take any form, provided the intended goal is assured (Crystal 1998). As easy refers to the smoothness function of an object, it is in the same vein that flexible points to the quality of an object for recipients to willingly surrender to external influences. Etisalat simply promotes the concept of adaptability, ductility and suppleness to sell the telecommunications' product to consumers.

\section{Conclusion}

As human beings are not static but advancing in civilisation on a daily basis so also is language developing for language is the hub of human existence. Thus, the development of language is a norm and rampant in society. Specifically, English as a language has undoubtedly proved that remark often, from the age of Chaucer to Shakespeare and the present day. In the Nigerian situation, English has been witnessing developments as users do incorporate many features into the language (Adetugbo 
1976; Awonusi 1990; Dalamu 2018c). Of significance is the contribution of the advertising industry whose sole responsibility relies heavily on creativity for persuasive purposes. In that course, the textual innovation has not only served as a convincing strategy of marketing but in one way or another, the irresistible behaviour has influenced readers in textual absorptions (Dalamu 2018d). And in-turn these assimilations have contributed to the development of the English language in our communities.

The communications of MTN and Etisalat, particularly, have demonstrated lexemic constructs that have a high impact on readers to submit to semantic thoughts that are posed to the public. Among others, it is impressive that formations such as (Y'ello, callertunez and MyCuctomer); and (0809ja, easystarter and easyblaze) have become the identities of MTN and Etisalat respectively. The acceptability of these logos has gone to an extent where subscribers can deploy these constructs ( $Y$ 'ello for $M T N$ and $0809 j a$ for Etisalat) interchangeably in matters regarding telecommunications in Nigeria.

The researcher observes that the advertiser's word formation procedures are somewhat based on the individual's discretion or judgment as language itself is characterised in arbitrariness. The construction, informed by the independent arbiter, might be as a result of enthusiasm for excitement, or perhaps, an attempt to make readers realise the formation with convenience. In that quest, the study reveals that, though innovative, imagination motivates advertising texts. This quality in a way exhibits the notion of the dynamism of language (Okoro 2008). Moreover, as MTN and Etisalat new lexicons have their roots in Y'ello, Link, easy and 9ja, most of their formations utilise phonemic devices to propagate and realise morphemic and graphemic facilities. Instances are [k] for Kulturefest, [z] for callertunez, [k] for easycliq, and $[j],[a]$ for Nigeria.

At this stage of linguistic accounts that researchers appreciate language more of a description than prescription, the study suggests that researcher could switch to act swiftly to continue to analyse more current issues in language development in Nigerian society. The findings of novel words could be codified and integrated officially to writing activities without any bias. As the analyst appreciates advertising professionals for these contributions, agencies in charge of language matters ought to encourage advertisers in this exploration of textual creativity. Also, the author can stress through this medium to persuade lexicographers that fascinating constructs of social prominence from the advertising industry in Nigeria and/or elsewhere need to be purified and incorporated into the dictionaries (general and specialised) as an augmentation of the development of English and by extension language developments at large. The adoption of such behaviour is civilisation.

\section{References}

Aartsm Bas and April McMahon, eds. (2006). The Handbook of English Linguistics. Oxford: Blackwell.

Adams, Valerie (2001). Complex Words in English. Harlow: Longman.

Adetugbo, Abiodun (1976). Nigerian English: Facts or Fiction? LARES, 6: 138-141.

Adetugbo, Abiodun (1997). English Phonetics: A Course Text. Yaba: University of Lagos Press. 
Akere, Funso (2004). Nigerian English in Sociolinguistic Perspectives: Users and Emerging Varieties. In Dadzie, Kofi and Awonusi, Olusegun, eds, Nigerian English: Influences and characteristics. Lagos: Concept Publication.

Akmajian, Adrian, Richard A. Demers and Robert M. Harnish (1984). Linguistics: An Introduction to Language and Communication. Cambridge, MA: MIT Press.

Almeida, Roberto G. De and Gary Libben (2005). Changing Morphological Structures: The Effect of Sentence Context on the Interpretation of Structurally Ambiguous English Trimorphemic Words. Language and Cognitive Processes 20, 1/2: 373-394.

Anderson, Stephen R. (1992). A-Morphous Morphology. Cambridge: Cambridge University Press.

Arnoff, Mark (1976). Word Formation in Generative Grammar. Cambridge, MA: MIT Press. Awonusi, Olusegun, V. (1990). Whose Standard, Which Model? Towards the Definition of a Standard Nigerian Spoken English for Teaching, Learning and Testing in Nigeria Spoken English for Teaching, Learning and Testing in Nigerian Schools. ITL Review of Applied Linguistics, 89 - 95.

Ball, Phill (2003). Morbo: The Story of Spanish Football. United Kingdom: WSC Books Limited.

Bamgbose, Ayo, Banjo Ayo, and Andrew Thomas (1995). New English: A West African Perspective. Ibadan: Mosuro Press.

Bauer, Laurie (1983). English Word-Formation. Cambridge: Cambridge University Press.

Bauer, Laurie (2001). Morphological Productivity, Cambridge: Cambridge University Press.

Bauer, Laurie (2006). Compound. In Brown, Keith, Anderson et al., eds., 719-726.

Bauer, Laurie and Antoinette Renouf (2001). A corpus-Based Study of Compounding in English, Journal of English Linguistics 29: 101-123.

Bauer, Laurie and Rodney Huddleston (2002). Lexical Word-Formation. In Huddleston and Pullum, 1621-1721.

Booij, Geert E. (2007). The Grammar of Word: An Introduction to Morphology). Oxford: Oxford University Press.

Booij, Geert E. and Jaap van Marle, eds. (2002). Yearbook of Morphology 2001. London: Kluwer.

Bolinger, Dwight (1987). Language, the Loaded Weapon: The Use and Abuse of Language Today. London: Longman.

Brown, Keith E. and Jim E. Miller (1980). Syntax: A Linguistic Introduction to Sentence Structure. London, England: Hutchinson.

Cook, Guy (2001). The Discourse of Advertising. New York: Routledge.

Carter, Ronald and Walter Nash (2013), Seeing Through Language, Lexington, KY: Blackwell.

Crystal, David (1998). Language Play. Chicago: University of Chicago Press.

Dadzie, A. B. Kofi and Victor O. Awonusi, eds. (2004). Nigerian English: Influences and Characteristics. Lagos: Concept Publications.

Dalamu, Taofeek O. (2017a). Narrative in Advertising: Persuading the Nigerian Audience within the Schemata of Storyline. AFEL, 7: 19-45. DOI: 10.1344/AFLM2017.7.2.

Dalamu, Taofeek O. (2017b). Maternal Ideology in an $M T N^{\circledR}$ Advertisement: Analyzing Socio-

Semiotic Reality as a Campaign for Peace. Journal of Language and Education 3, 4: 16-26. DOI: $10.17323 / 2411-7390-2017-3-4-16-26$.

Dalamu, Taofeek O. (2017c). A Discourse Analysis of Language Choice in MTN ${ }^{\circledR}$ and Etisalat $^{\circledR}$ Advertisements in Nigeria (PhD Thesis, University of Lagos, Yaba, Lagos) 
Dalamu, Taofeek O. (2018a). Akèrègbè, Resourcing the Past, Communicating the Present in Shared Cultural Knowledge: A Case Study of GTB Advertising. Communication 12(1), 113-137.

Dalamu, Taofeek O. (2018b). Exploring Advertising Text in Nigeria within the Framework of Cohesive Influence, Styles of Communication 10,1: 74-97.

Dalamu, Taofeek O. (2018c). Advertising Communication: Constructing Meaning Potential through Disjunctive Grammar. Anagramas Rumbos y Sentidos De La Communicación 17(1) (in press).

Dalamu, Taofeek O. (2018d). Euphemism: The Commonplace of Advertising Culture. Acta Scientiarum. Language and Culture (in press).

Dalton-Puffer, Christiane and Plag, Ingo (2001). Category-wise, Some Compound-Type Morphemes Seem to Be Rather Suffix-Like: on the Status of -ful, -type, and-wise in Present Day English. Folia Linguistica XXXIV: 225-244.

De Beaugrande, Robert (1991). Linguistic Theory: The Discourse of Fundamental Works. London and New York: Longman.

Deloitte UK. (2016). Deloitte Football Money League 2016. Retrieved from https://www2. deloitte.com/content/dam/Deloitte/uk/Documents/sports-business-group/uk-deloittesport-football-money-league-2016.pdf

Denham, Kristin and Anne Lobeck (2013). Linguistics for Every One: An Introduction. Singapore: Wadsworth, Cengage Learning.

DeSantis, Nick (2016). The 20 Most Valuable Soccer Teams of 2016, Visualized. Forbes. Retrieved from https:/www.forbes.com/sites/nickdesantis/2016/05/11/the-20-most-valuable-soccer-teams-of-2016-visualized/

Eaude, Michael (2008). Catalonia: A Cultural History. Oxford: Oxford University Press.

Ferrand, Allain and Scott McCarthy (2008). Marketing the Sports Organization: Building Networks and Relationships. London and New York: Routledge.

Gimson, Alfred C. (1985). A Practical Course of English Pronunciation. London: Edward Arnold.

Halliday, Michael A. K. and Christian M.I.M. Matthiessen (2014). Halliday's Introduction to Functional Grammar. Abingdon, Oxon: Routledge.

Hammond, Michael and Michael Noonan, eds. (1988). Theoretical Morphology: Approaches in Modern Linguistics. San Diego: Academic Press.

Hay, Jennifer (2001). Lexical Frequency in Morphology: Is Everything Relative? Linguistics 39.4: 1041-1070.

Haspelmath, Martin (2002). Understanding Morphology. London: Arnold.

Hinnebusch, Thomas. J. (1979). Swahili. In T. Shopen, ed. Languages and Their Status. Winthrop: Cambridge.

Horn, Elizabeth A. (2010). Poetic Organization and Poetic License in the Lyrics of Hank Williams, SR. and Snoop Dogg. [PhD Dissertation. Austin, University of Texas]. Retrieved from https://repositories.lib.utexas.edu/bitstream/handle/2152/ETDUT-2010-12-2425/HORN-DISSERTATION.pdf?sequence=1

Jackson, Howard, and Etienne Ze Amvela (2005). Words, Meaning and Vocabulary: An Introduction to Modern English Lexicology. London: Continuum

Jensen, John T. (1990). Morphology: Word Structures in Generative Grammar. Amsterdam and Philadelphia: John Benjamins.

Jowitt, David (1991). Nigerian English Usage: An introduction. Nigeria: Longman.

Kachru, Braj B. (2017). World Englishes and Culture Wars. Cambridge Approaches to Language Contact. Cambridge: Cambridge University Press. 
Katamba, Francis and John Stonham (2006). Morphology. New York: Library of Congress.

King, Anthony (2003). The European Ritual: Football in the New Europe. Herausgeber: Ashgate Publishing, Limited.

Ladefoged, Peter (1982). A Course in Phonetics. Harcourt Brace Jovanovich.

Leech, Geoffrey N. (1966). English in Advertising: A Linguistic Study of Advertising in Great Britain. London: Longman.

Leech, Geoffrey N., Paul Rayson and Andrew Wilson (2001). Word Frequencies in Written and Spoken English, Harlow: Longman.

Libben, Gary (2003). Morphological Parsing and Morphological Structure. In E. Assink and D. Sandra, eds, 221-239.

Lieber, Rochelle (2004). Morphology and Lexical Semantics. Cambridge University Press, Cambridge.

Lieber Rochelle (2005). English Word-Formation Processes. Observations, Issues, and Thoughts. On Future Research. In P. Štekauer and R. Lieber, eds, 375-427.

Lieber, Rochelle. (2010). Introducing Morphology. Cambridge: Cambridge University Press.

Lieber, Rochele and Pavol Štekauer, eds. (2011). The Oxford Handbook of Compounding. Oxford: OUP.

Matthew, Peter H. (1974). Morphology: Introduction to the Word Structure. Cambridge: Cambridge University Press.

McGregor, William B. (2011). A Fundamental Misconception of Modern Linguistics. Acta Linguistica Hafniensia 35, 39-64.

Murray, Bill (1998). The World's Game: A History of Soccer. Urbana and Chicago: University of Illinois Press.

Myers, Greg (1994). Words in Ads. London: Arnold.

Napoli, Donna J. (1996). Linguistics. Oxford: Oxford University Press.

Nolda, Andreas (2014). Word-Formation Types Definition, Identification, Classification. Retrieved from http://andreas.nolda.org.

O’Connor, Joseph D. (1973). Phonetics. London: Penguin.

O'Grady, William, John Archibald, Mark Aronoff and Jenie Rees-Miller (2005). Contemporary Linguistics: An Introduction. (New York: Bedford/St. Martin's.

Okoro, Oko (2006). Category Shift in Nigerian English. LARES: A Journal of Language \& Literary Studies, 15(1\&2): 10 - 16.

Okoro, Oko (2008). Exploring Collocations in Nigerian English Usage. In Adeyemi Daramola and Olubukola Olugasa, eds., 113-140.

Packard, Vance (2007). The Hidden Persuader. Brooklyn, NY: IG Publishing.

Payne, Thomas E. (2006). Exploring Language Structure: A Student Guide. Cambridge: CambridgeUniversity Press.

Plag, Inglo (2003). Word-Formation in English. Cambridge: Cambridge University.

Pride, John B., ed. (1982). New Englishes. Rowley, Massachusetts: Newbury House.

Ricks, N. and M. Mash, (1969). Patterns in English: A Unified Program for Consumption. New York: Charles Scribner's Sons.

Robins, Robert H. (1989). General Linguistics: An Introductory Survey. London: Routledge. Roy, Joaquin (2001). Football, European integration, National Identity: The Case of FC Barcelona. European Community Studies Association. Retrieved from http://aei.pitt. edu/2175/1/002253_1.PDF.

Ruzaitè, Jūratè (2012). Studying Word-Formation in English. Kaunas: Vytautas Magnus University.

Selkirk, Elisabeth O. (1982). The Syntax of Words. MIT Press, Cambridge. 
Shubert, Adrian (1990). A Social History of Modern Spain. London and New York: Routledge.

Spencer, Andrew (1992). Morphological Theory: An Introduction to Word Structure in Generative Grammar. London: Basil Blackwell.

Stewart, Thomas and Nathan Vaillette (2001). Language Files. Ohio State University Press, Columbus.

Stockwell, Robert, and Donka Minkova (2001). English Words: History and Structure. Cambridge: Cambridge University Press.

Sugioka, Yoko (2011). Nominalisation Affixes and Multi-Modularity of Word-Formation. Philadelphia: John.

Thompson, Geoff (2014). Introducing Functional Grammar. Abingdon, Oxon: Routledge.

Ubahkwe, Emmanuel, ed. (1979). Varieties and Functions of English in Nigeria. Ibadan: NESA/OUP.

Vikner, Carl and Sten Vikner (2008). Hierarchical Morphological Structure and Ambiguity. In Merete Birkelund, Maj-Britt Mosegaard Hansen and Coco Norén, eds., 541-560.

Wikipedia (2016). MTN. Retrieved from https://en.wikipedia.org/wiki/MTN.

Wimsatt, William K. and Monroe C. Beardsley (1954). The Verbal Icon: Studies in the Meaning of Poetry. Lexington KY: University of Kentucky Press.

Xhignesse, Michel-Antoine (2016). The Trouble with Poetic Licence. British Journal of Aesthetics 56 (2),149-161. DOI: https://doi.org/10.1093/aesthj/ayv053. Retrieved from https:/academic.oup.com/bjaesthetics/article-abstract/56/2/149/2195135/The-Trouble-with-Poetic-Licence?redirectedFrom $=$ PDF.

Yule, George (1985). The Study of Language. Cambridge: Cambridge University Press.

Yule, George (2016). The Study of Language. Cambridge: Cambridge University Press.

Zapata Becerra, Argenis. A. (2000). Handbook of General and Applied Linguistics. Mérida, Venezuela: Trabajo de Ascenso sin publicar.

Zapata Becerra, Argenis. A. (2007). Types of Words and Word-Formation Processes in English: Inglés IV. Retrieved from http://webdelprofesor.ula.ve/humanidades/azapata/materias/english_4/unit_1_types_of_words_and_word_formation_processes.pdf. 